\title{
Remediation of Childhood Math Anxiety and Associated Neural Circuits through Cognitive Tutoring
}

\author{
Kaustubh Supekar, ${ }^{1}$ Teresa Iuculano, ${ }^{1}$ Lang Chen, ${ }^{1}$ and Vinod Menon ${ }^{1,2,3}$ \\ Departments of ${ }^{1}$ Psychiatry and Behavioral Sciences and ${ }^{2}$ Neurology and Neurological Sciences, Stanford University, Stanford, California 94305 , and \\ ${ }^{3}$ Stanford Neurosciences Institute, Stanford, California 94305
}

\begin{abstract}
Math anxiety is a negative emotional reaction that is characterized by feelings of stress and anxiety in situations involving mathematical problem solving. High math-anxious individuals tend to avoid situations involving mathematics and are less likely to pursue science, technology, engineering, and math-related careers than those with low math anxiety. Math anxiety during childhood, in particular, has adverse long-term consequences for academic and professional success. Identifying cognitive interventions and brain mechanisms by which math anxiety can be ameliorated in children is therefore critical. Here we investigate whether an intensive 8 week one-to-one cognitive tutoring program designed to improve mathematical skills reduces childhood math anxiety, and we identify the neurobiological mechanisms by which math anxiety can be reduced in affected children. Forty-six children in grade 3 , a critical early-onset period for math anxiety, participated in the cognitive tutoring program. High math-anxious children showed a significant reduction in math anxiety after tutoring. Remarkably, tutoring remediated aberrant functional responses and connectivity in emotion-related circuits anchored in the basolateral amygdala. Crucially, children with greater tutoring-induced decreases in amygdala reactivity had larger reductions in math anxiety. Our study demonstrates that sustained exposure to mathematical stimuli can reduce math anxiety and highlights the key role of the amygdala in this process. Our findings are consistent with models of exposure-based therapy for anxiety disorders and have the potential to inform the early treatment of a disability that, if left untreated in childhood, can lead to significant lifelong educational and socioeconomic consequences in affected individuals.
\end{abstract}

Key words: amygdala; anxiety; childhood; fMRI; intervention; plasticity

Significance Statement

Math anxiety during early childhood has adverse long-term consequences for academic and professional success. It is therefore important to identify ways to alleviate math anxiety in young children. Surprisingly, there have been no studies of cognitive interventions and the underlying neurobiological mechanisms by which math anxiety can be ameliorated in young children. Here, we demonstrate that intensive 8 week one-to-one cognitive tutoring not only reduces math anxiety but also remarkably remediates aberrant functional responses and connectivity in emotion-related circuits anchored in the amygdala. Our findings are likely to propel new ways of thinking about early treatment of a disability that has significant implications for improving each individual's academic and professional chances of success in today's technological society that increasingly demands strong quantitative skills.

\section{Introduction}

Math anxiety impairs performance on a wide range of cognitive tasks involving numerical problem solving and is a prominent cause of math difficulties in children (Ashcraft and Krause, 2007).

\footnotetext{
Received Feb. 26, 2015; revised Aug. 3, 2015; accepted Aug. 5, 2015.

Author contributions: K.S. and V.M. designed research; K.S. performed research; V.M. contributed unpublished reagents/analytic tools; K.S., T.I., and L.C. analyzed data; K.S. and V.M. wrote the paper.

The authors declare no competing financial interests.

This work was supported by grants from the National Institutes of Health (HD059205, HD047520) and by a National Alliance for Research on Schizophrenia and Depression Young Investigator Award and an Atherton Investigator Award to K.S. We thank Lynn Fuchs, Sarit Ashkenazi, Dietsje Jolles, Rosy Karna, and Katie Cheng for assistance with the study.
}

Math anxiety during early childhood also has adverse long-term consequences for career choice, employment, and professional success (Hembree, 1990; Ma, 1999). Furthermore, math anxiety is highly prevalent, affecting nearly $50 \%$ of grade-school children in the United States alone (Beilock and Willingham, 2014). Given its widespread prevalence and detrimental long-term impact on academic performance and professional development, it is essen-

Correspondence should be addressed to either of the following: Dr. Kaustubh Supekar, Stanford University School of Medicine, 401 Quarry Rd., Stanford, CA 94305. E-mail: ksupekar@stanford.edu; or Dr. Vinod Menon, Stanford University School of Medicine, 401 Quarry Rd., Stanford, CA 94305. E-mail: menon@stanford.edu. DOI:10.1523/JNEUROSCI.0786-15.2015

Copyright $\odot 2015$ the authors $\quad 0270-6474 / 15 / 3512574-10 \$ 15.00 / 0$ 
a

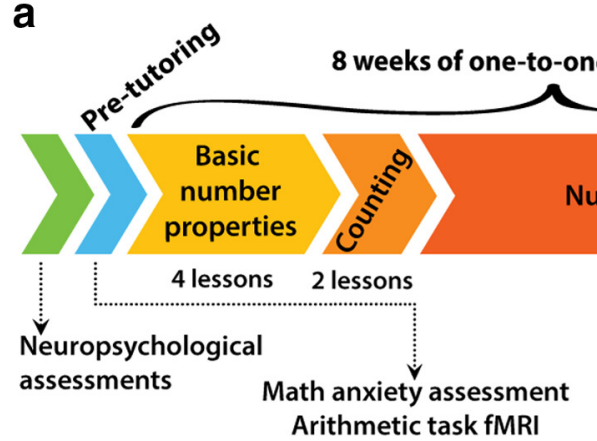

b

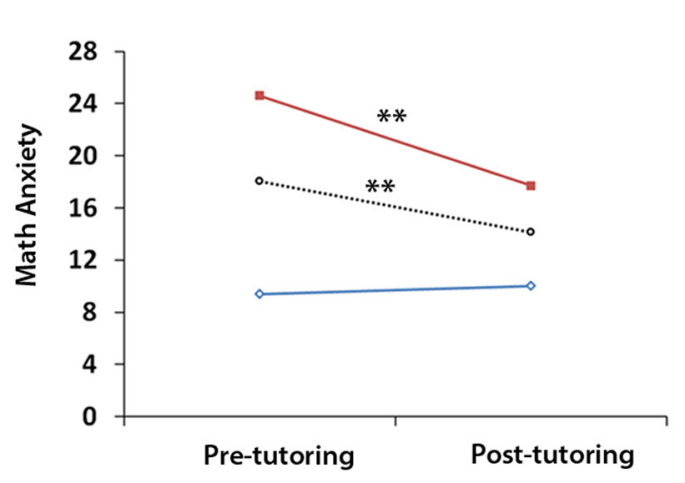

Figure 1. Eight weeks of one-to-one math tutoring reduces math anxiety in high math-anxious children. $\boldsymbol{a}$, Study design. Before tutoring, all children underwent an extensive battery of neuropsychological assessments for $\mathrm{IQ}$, academic achievement, and working memory. Additionally, before tutoring, each child underwent an fMRI scan session during which they had to verify addition equations (Addition task; e.g., $3+4=7$ ) and assess the validity of number identity expressions (Control task; e.g., $7=$ 7). Upon successful completion of the aforementioned sessions, children went through an intensive 8 week one-to-one tutoring program focused on conceptual aspects of number knowledge and speeded practice on efficient counting strategies and systematic learning of number families (i.e., all the problems that summed to 5 and the corresponding subtraction problems) delivered through 22 lessons of increasing difficulty. Tutoring sessions occurred three times per week and were each $\sim 40-50$ min in duration. After 8 weeks of tutoring, all children underwent a second MRI scan session. Additionally, math anxiety at pre-tutoring and post-tutoring sessions was assessed in each child using the SEMA. Pre-tutoring SEMA scores were used to delineate participants into HMA and LMA groups. $\boldsymbol{b}$, Math-anxiety levels, as measured by the SEMA, decreased significantly with tutoring. There was a significant interaction between Time (pre-tutoring vs post-tutoring) and Group (HMA vs LMA) with HMA group showing larger reductions in math-anxiety levels with tutoring, compared with the LMA group $\left(^{* *} p<0.01\right)$.

tial to identify ways to alleviate math anxiety in children (Maloney and Beilock, 2012). Recent research has shown that childhood math anxiety is associated with aberrant functional responses in brain regions and circuits important for processing negative emotions (Young et al., 2012).

Although the negative consequences of math anxiety are well understood, to date there have been no studies of interventions for remediating math anxiety in children. One possible approach to anxiety reduction is based on well validated studies of behavioral exposure-based therapy for anxiety disorders. Multiple meta-analyses have demonstrated the efficacy of exposure-based therapy for treating anxiety disorders including phobias (Wolitzky-Taylor et al., 2008) and post-traumatic stress disorder (Van Etten and Taylor, 1998). The basic premise of these successful interventions is that repeated exposure to distressing stimuli and fearful situations ultimately brings about a decrease in the individual's negative response to the stimulus (Abramowitz et al., 2011). Accordingly, we reasoned that intensive cognitive tutoring programs designed to improve mathematical skills in children could also help reduce negative emotions associated with math by virtue of mere exposure.

In the past two decades, cognitive tutoring programs designed to improve basic arithmetic fluency have been developed and tested in classroom and one-to-one tutoring settings (Fuchs et al.,
2008). Although these targeted interventions have been shown to be effective in remediating poor mathematical skills, it is not known whether sustained exposure and training with mathematical stimuli can also reduce math anxiety. Addressing this question is critical for gaining a more comprehensive understanding of math anxiety and the mechanisms by which training and exposure increase cognitive skills while at the same time reducing negative emotions.

Here, we investigate whether an intensive 8 week one-to-one math tutoring program (Fuchs et al., 2013; Fig. 1A) can reduce math anxiety in elementary school children, and we identify the neurobiological mechanisms by which math anxiety is ameliorated in affected children. Tutoring sessions occurred three times per week and each session lasted $\sim 40-50$ min. Functional MRI (fMRI) data during arithmetic problem solving and data on math-anxiety levels, assessed using the Scale for Early Mathematics Anxiety (SEMA; Wu et al., 2012), were acquired from each participant before and after tutoring. We examined behavioral as well as functional brain responses and circuits in each child before and after tutoring, and compared across the high math-anxiety (HMA) and low math-anxiety (LMA) groups. Based on evidence from previous studies of exposure-based interventions for treating anxiety (Abramowitz et al., 2011) and theoretical models of math anxiety (Maloney and Beilock, 2012), we hypothesized that intensive math tutoring would reduce math anxiety while simultaneously improving mathematical performance in children with HMA. The only previous study to directly investigate the neural correlates of math anxiety in young children reported that children with math anxiety show hyperactive amygdala responses and decreased connectivity of the amygdala with brain regions involved in emotion regulation (Young et al., 2012). Based on previous studies in both humans (Hauner et al., 2012) and animal models (Phelps and LeDoux, 2005; Myers and Davis, 2007) that found that repeated exposure to anxiety-provoking stimuli reduces brain activation and neuronal firing rates in the amygdala, we predicted that 8 weeks of intensive math tutoring would remediate amygdala hyperactivity and impaired amygdalar circuits in children with math anxiety. Finally, we hypothesized that changes in amygdalar circuits would be associated with behavioral outcomes such that children who exhibited greater tutoring-induced changes would show larger decreases in math anxiety with tutoring.

\section{Materials and Methods}

\section{Participants}

A total of 46 children (21 males, 25 females) in the third grade (ages 7-9 years old) were initially recruited from multiple school districts in the San Francisco Bay area. All participants were right handed and without medical, neurological, or psychiatric illness. Informed consent was ob- 
Table 1. Demographic and neuropsychological measures in HMA and LMA groups ${ }^{a}$

\begin{tabular}{lccl}
\hline Measure & HMA & LMA & $p$ value \\
\hline Age (years) & $8.51( \pm 0.51)$ & $8.68( \pm 0.37)$ & 0.34 \\
Gender & 6 males; 8 females & 6 males; 8 females & 1 \\
WASI & & & \\
$\quad$ Verbal IQ & $104.42( \pm 12.22)$ & $104.36( \pm 11.94)$ & 0.92 \\
$\quad$ Performance IQ & $103.50( \pm 11.39)$ & $105.79( \pm 15.61)$ & 0.21 \\
$\quad$ Full IQ & $104.25( \pm 7.73)$ & $105.57( \pm 9.94)$ & 0.42 \\
WIAT-II & & & \\
$\quad$ Numerical Operations & $91.16( \pm 11.76)$ & $89.24( \pm 12.04)$ & 0.20 \\
$\quad$ Math Reasoning & $93.83( \pm 10.41)$ & $95.79( \pm 10.93)$ & 0.38 \\
$\quad$ Word reading & $99.75( \pm 10.21)$ & $101.29( \pm 10.19)$ & 0.42 \\
$\quad$ Reading Comprehension & $104( \pm 11.58)$ & $104.86( \pm 10.83)$ & 0.78 \\
WMTB-C & & & \\
$\quad$ Digit Recall & $96.46( \pm 11.85)$ & $101.43( \pm 17.45)$ & 0.39 \\
$\quad$ Block Recall & $92.38( \pm 10.85)$ & $88.30( \pm 19.54)$ & 0.52 \\
$\quad$ Count Recall & $87.08( \pm 15.92)$ & $76.46( \pm 15.15)$ & 0.11 \\
$\quad$ Backward Digit Recall & $94.76( \pm 14.56)$ & $87.85( \pm 9.39)$ & 0.16 \\
\hline
\end{tabular}

aThe groups did not differ in age, 10 , math, reading, or working-memory abilities.

tained from the legal guardian of the child and all study protocols were approved by the Stanford University Review Board. All participants were volunteers and were treated in accordance with the American Psychological Association's Ethical Principles of Psychologists and Code of Conduct.

Nine children had to be excluded from the study because they had incomplete behavioral data. A further nine had to be excluded from the fMRI part of the study because they did not meet criteria for (1) inscanner motion parameters (total frames interpolated, $<20 \%$ ) and (2) in-scanner accuracy performance $(>50 \%)$. This resulted in a total sample size of 28 children with high-quality fMRI and behavioral pretutoring and post-tutoring data. A median split based on pre-tutoring scores on the SEMA test was used to divide participants into HMA and LMA groups (Young et al., 2012). The HMA and LMA groups did not differ in age, IQ, mathematical, reading, or working-memory abilities (Table 1).

\section{Overall study design}

Figure $1 A$ illustrates the study design. Demographic, neuropsychological, cognitive, and brain-imaging measures were acquired from each participant before tutoring. Before 8 weeks of one-to-one math tutoring, participants underwent an MRI scanning session, which included both an fMRI as well as a structural MRI (sMRI) protocol. The fMRI task consisted of an arithmetic problem-solving task (Addition task) and a number identification task (Control task). After successful completion of the MRI scanning session, children started the 8-week math tutoring program. Tutoring sessions occurred three times per week and were each $\sim 40-50 \mathrm{~min}$ in duration. A second MRI scanning session using the same protocols took place immediately after 8 weeks of tutoring. Additionally, the math-anxiety level of each participant at pre-tutoring and post-tutoring sessions was assessed using the SEMA (Wu et al., 2012).

\section{Neuropsychological assessments}

Each child participated in a neuropsychological assessment session in which they were tested on the Wechsler Abbreviated Scale of Intelligence (WASI; Wechsler, 1999), the Wechsler Individual Achievement Test (WIAT-II; Wechsler, 2001), and the Working Memory Test Battery for Children (WMTB-C; Pickering and Gathercode, 2001). Full-scale IQ was determined using the WASI; academic achievement in reading and mathematics was assessed using the WIAT-II; working memory was assessed using the WMTB-C. These standardized measures were acquired before tutoring and were not readministered because of their limited validity when repeated within a year.

\section{Tutoring sessions}

All children took part in an 8 week math tutoring program adapted from MathWise (Fuchs et al., 2008, 2013; Powell et al., 2009). The program combined conceptual instruction with speeded retrieval of arithmetical facts. Like MathWise, our protocol involved a total of 15-20 h of tutoring, but it was condensed to 8-9 weeks with longer sessions to equate overall time on tutoring. Specifically, the tutoring consisted of 22 lessons of increasing difficulty. Lessons $1-4$ reviewed the operations of addition and subtraction with simple operands, such as 0,1 , and 2 , and small ties problems (from $1+1$ to $6+6$ and their corresponding subtraction facts, such as $12-6$ ). These lessons also had a conceptual component: they reviewed the commutative property of addition (i.e., changing the order of the operands does not change the resulting sum), as well as the additive identity property of zero (i.e., adding zero as an operand does not change the number's value). Finally, the first four lessons focused on familiarizing the child with math manipulatives (i.e., number line and blocks in a circle).

Lessons 5 and 6 taught the "min strategy" for addition (i.e., start counting from the larger number and count up with the smaller number) and the "missing addend strategy" for subtraction (i.e., start with the smaller number and count up to the larger number). During lessons $7-22$, children practiced these strategies with progressively more difficult problems. They started out with all addition problems that summed to 5 and the corresponding subtraction problems. By the end of the program, they learned addition problems that summed to 18 and their corresponding subtraction problems. All these lessons (i.e., "number families") followed the same structure: (1) warm-up physical flashcards to review previously trained math problems; (2) number knowledge review, including the use of manipulatives and counting strategies; (3) a lesson worksheet that introduced the new math problems (i.e., the new number families); (4) a physical math game, which alternated between Math Bingo, in which the child has to quickly calculate the sum of a given problem (i.e., $6+4$ ) and verify whether the answer (i.e., 10) appears in his/her bingo card; Math War, in which the child and the tutor have to each draw two cards from a given deck of cards picturing the digits $0-9$ and quickly calculate the sum of the digits with the goal of ending up with the greatest sum; and Treasure Hunt, in which the child has to draw from a deck of cards picturing math problems, solve the given problem on each card, and write down the equation and the correct answer on the stepping stones of the "treasure map" provided; (5) untimed computerized and timed physical flashcards combining material from both current and previous lessons; and (6) a review worksheet for the number family covered that day. Since scanning occurred only on weekends, children who completed lesson 22 early in the week took part in additional review sessions $(\leq 3)$.

\section{fMRI experiment}

Participants performed two runs of an event-related fMRI experiment involving (1) addition and (2) control number identification problems. Within each run, 12 arithmetic and 12 nonarithmetic number identification problems were presented, and the order of stimulus presentation was randomized across participants. The event-related design also included a total of six rest intervals of $10 \mathrm{~s}$ each. These occurred at jittered intervals during each run to achieve an optimal event-related fMRI design (Kao et al., 2009).

In the Addition task condition, participants were presented with an equation involving two single-digit operands and asked to indicate, via a button box, whether the answer shown was correct or incorrect (e.g., $3+$ $4=8$ ). Tie problems, such as $5+5=10$, were excluded as were problems with 1 or 0 as operands. The larger operand was equally likely to appear in the first or second position. In half of the problems, the answers presented were correct (e.g., $2+4=6$ ); in the remaining half, the answers presented deviated from the correct solution by \pm 1 or \pm 2 (e.g., $3+5=$ 7; Ashcraft and Battaglia, 1978).

In the Control Number Identification task condition, participants were asked to indicate whether an equation involving two single-digit numbers was correct or incorrect (e.g., $7=7$ or $7=8$ ).

In both task conditions, problems were presented horizontally in green lettering on a black background. Each trial started with a fixation asterisk that lasted $0.5 \mathrm{~s}$. An addition or control problem was then presented, during which time the participant made a response to indicate whether the equation was correct or not. After the response, the problem 
disappeared from the screen and a blank screen appeared until the time window was filled to $9.5 \mathrm{~s}$.

To control for potential exposure effects, each participant was presented with a unique set of problems during the pre-tutoring and posttutoring fMRI sessions. These problems were derived by manipulating the operands and the putative resultant and by changing the order of operands. For example, if a participant saw $2+4=6$ and $3+4=8$ during the pre-tutoring scan, he/she would be presented with $3+5=8$ and $4+2=7$ at the post-tutoring scan.

\section{Brain imaging}

fMRI data acquisition. fMRI data were acquired using whole-brain imaging with a $2^{\star}{ }^{\star}$-sensitive gradient echo spiral in/out pulse sequence (Preston et al., 2010) at a Signa LX (GE Medical Systems) 3T scanner with the following parameters: echo time $(\mathrm{TE})=30 \mathrm{~ms}$; repetition time $(\mathrm{TR})=$ $2 \mathrm{~s}$; flip angle, $80^{\circ}$; field-of-view, $200 \mathrm{~mm}$; 29 axial-oblique slices parallel to the anterior commissure-posterior commissure axis; dimensions, $3.125 \times 3.125 \times 4 \mathrm{~mm}$ with $0.5 \mathrm{~mm}$ skip. To reduce blurring and signal loss from field inhomogeneity, an automated high-order shimming method based on a spiral acquisition was used before the acquisition of fMRI scans (Kim et al., 2002). Cushions were placed around participants' heads to minimize head movement.

sMRI data acquisition. High-resolution T1-weighted images were acquired for each child at both scanning sessions (i.e., pre-tutoring and post-tutoring) to facilitate anatomical localization of functional (fMRI) maps (see below). A spoiled-grass-gradient-recalled inversion recovery 3D MRI sequence with the following parameters was used: TI $=300 \mathrm{~ms}$, $\mathrm{TR}=8.4 \mathrm{~ms} ; \mathrm{TE}=1.8 \mathrm{~ms}$; flip angle, $15^{\circ} ; 22 \mathrm{~cm}$ field of view; 132 slices in coronal plane; $256 \times 192$ matrix; number of excitations, 2; acquired resolution, $1.5 \times 0.9 \times 1.1 \mathrm{~mm}$.

\section{fMRI preprocessing}

Data were preprocessed in SPM8 (http://www.fil.ion.ucl.ac.uk/spm/). To allow for signal equilibration, the first five volumes were not analyzed. A linear shim correction was applied separately for each slice during reconstruction using a magnetic field map acquired automatically by the pulse sequence at the beginning of the scan (Glover and Lai, 1998). Images were realigned to correct for motion, corrected for errors in slice timing, coregistered to each individual structural T1 image, spatially transformed to standard stereotaxic space (based on the Montreal Neurological Institute coordinate system), resampled every $2 \mathrm{~mm}$ using sinc interpolation, and smoothed with a $6 \mathrm{~mm}$ full-width half-maximum Gaussian kernel to decrease spatial noise before statistical analysis. For coregistration, the individual's highest quality-rated (i.e., either pretutoring or post-tutoring) sMRI sequence was used.

Translational movement in millimeters $(x, y, z)$ and rotational motion in degrees (pitch, roll, yaw) were calculated based on the SPM8 parameters for motion correction of the functional images for each subject. Mean scan-to-scan displacement of movement did not exceed $1 \mathrm{~mm}$ for all participants in either session (i.e., pre-tutoring/post-tutoring). To correct for deviant volumes resulting from spikes in movement, we used despiking procedures similar to those implemented in Analysis of Functional NeuroImages (Cox, 1996). Volumes with movement exceeding 0.5 voxels $(1.562 \mathrm{~mm})$ or spikes in global signal exceeding $5 \%$ were interpolated using adjacent scans.

\section{fMRI data analysis}

General linear model. Task-related brain activation was identified using the general linear model (GLM) implemented in SPM8. At an individual level, brain activity related to task conditions was modeled using a boxcar function of $9.5 \mathrm{~s}$ (i.e., the whole length of any given trial) with a canonical hemodynamic response function and a temporal derivative to account for voxelwise latency differences in hemodynamic response. Voxelwise contrast and $t$-statistics images were generated for each participant by contrasting arithmetic problem solving (Addition) versus number identity verification (Control) conditions and were averaged across the two runs. Both correct and incorrect trials were modeled in the GLM (four subconditions: Addition correct, Control correct, Addition incorrect, Control incorrect). The final voxelwise contrast and $t$-statistic maps were generated on the first two subconditions only: Addition correct and Control correct.
At a group level, differences in brain activation between the HMA and LMA groups were compared at both sessions (pre-tutoring and posttutoring separately) using an ANOVA model on contrast images of the Addition versus Control conditions. Group differences were measured at the whole-brain level and significant clusters of activation were identified using a height threshold of $p<0.01$, with familywise error (FWE) correction for multiple spatial comparisons at the cluster level $(p<0.01$; spatial extent, 128 voxels) based on Monte Carlo simulations. Based on our a priori hypotheses, a small-volume correction was applied for identifying significant clusters in the amygdala $(p<0.01)$, as is commonly used in functional neuroimaging studies of this brain structure (Vuilleumier et al., 2001; Hooker et al., 2006; Gamer and Büchel, 2009; Young et al., 2012).

Psychophysiological interaction model. Psychophysiological interaction (PPI) connectivity analysis (Friston et al., 1997) was performed using a 4-mm-radius sphere centered in the right amygdala cluster where tutoring-induced decreases in functional responses predicted decreases in anxiety levels in HMA children $(x=30 \mathrm{~mm}, y=2 \mathrm{~mm}, z=-20 \mathrm{~mm})$. We used a standard PPI analysis procedure (Pessoa et al., 2002; Valet et al., 2004; Summerfield et al., 2006; Coccaro et al., 2007; Young et al., 2012) that explicitly models and controls for overall task activation and, as such, models effective rather than synchronized task-related coactivation (Friston et al., 1997). Specifically, our PPI analysis used three regressors: (1) a physiological variable representing the deconvolved time series within the seed region; (2) a psychological variable representing the two types of conditions-Addition arithmetic problem solving and Control number identity verification-; and (3) a PPI term that represented the Hadamard cross-product of the first two regressors. PPI analyses were performed at the individual participant level and contrast images corresponding to Addition, versus Control, conditions were entered into an ANOVA model to compare task-related differences in effective connectivity between the HMA and LMA groups (i.e., between-factors variable), pre-tutoring versus post-tutoring (i.e., within-factors variable). Significant clusters were thresholded at $p<0.01$, with FWE corrections for multiple spatial comparisons ( $p<0.01$; spatial extent, 128 voxels) based on Monte Carlo simulations. Based on our a priori hypotheses, a smallvolume correction was applied for identifying significant clusters in the amygdala ( $p<0.01$; Vuilleumier et al., 2001; Hooker et al., 2006; Gamer and Büchel, 2009; Young et al., 2012).

Multivariate prediction analysis. To investigate whether changes in functional brain response predicted individual differences in decreases of math anxiety with tutoring, we conducted a support-vector regression (SVR) analysis using change in functional activation with tutoring as the independent variable and change in anxiety levels with tutoring as the dependent variable. We focused on brain regions that showed greater changes in functional activation with tutoring in HMA, compared with LMA, children. We used SVR with the default settings of $C=1$ and $\nu=$ 0.05 , as implemented in the LIBSVM (A Library for Support Vector Machines) Toolbox (http://www.csie.ntu.edu.tw/ cjlin/libsvm/). We first estimated $R^{2}$, using the leave-one-out cross-validation procedure. Each sample was designated the test sample in turns, while the remaining samples were used to train the SVR predictor. The decision function derived from the training sample was then used to make a real-valued prediction about the test sample. $R^{2}$ was computed based on the observed and predicted values. Finally, the statistical significance of the SVR model was assessed using nonparametric analysis. The empirical null distribution of $R^{2}$ was estimated by generating 10,000 surrogate datasets under the null hypothesis that there was no association between change in anxiety levels with tutoring and change in functional activation patterns with tutoring. Each surrogate dataset $D_{i}$ of size equal to the observed dataset was generated by permuting the labels (change in anxiety levels with tutoring) on the observed data points. The SVR model was fitted to predict labels of each surrogate dataset $D_{i}$. $R_{i}^{2}$ was computed using the actual labels of $D_{i}$ and predicted labels. This procedure produces a null distribution of $R^{2}$ of the SVR model. The statistical significance ( $p$ value) of the model was then determined by counting the number of $R_{i}^{2}$ greater than $R^{2}$ and dividing that count by the number of $D_{i}(10,000)$. 


\section{Results}

Eight weeks of one-to-one math tutoring reduces math anxiety in high math-anxious children

We first assessed changes in math anxiety elicited by 8 weeks of one-to-one math tutoring. Math-anxiety levels, as measured by SEMA, decreased significantly with tutoring, $\left(F_{(1,35)}=5.23, p=\right.$ $\left.0.023, \eta_{p}^{2}=0.14\right)$. Notably, there was a significant interaction between time (pre-tutoring vs post-tutoring) and group (HMA vs LMA; $F_{(1,35)}=7.67, p=0.009, \eta_{p}^{2}=0.18$; Fig. $\left.1 B\right)$. When stratified by the pre-tutoring math-anxiety level, HMA children showed a significant decrease in math-anxiety levels after tutor$\operatorname{ing}\left(F_{(1,20)}=12.07, p=0.002, \eta_{p}^{2}=0.38\right)$, whereas LMA did not show such effect $\left(F_{(1,15)}=0.11, p=0.747\right)$. Interestingly, decreases in anxiety levels with tutoring correlated with pretutoring anxiety levels $\left(r_{(37)}=0.366, p=0.026\right)$, indicating that children with higher levels of pre-tutoring math anxiety benefitted the most in terms of reductions in negative emotional responses to math.

\section{Eight weeks of one-to-one math tutoring improves arithmetic} performance

We next examined changes in math performance following 8 weeks of one-to-one math tutoring. As predicted by evidence from previous studies (Powell et al., 2009; Fuchs et al., 2013; Supekar et al., 2013), we found that performance on the arithmetic problem-solving task improved significantly after tutoring. Performance gains were observed for both accuracy $\left(F_{(1,27)}=\right.$ 24.71, $\left.p<0.001, \eta_{p}^{2}=0.46\right)$ and reaction times $\left(F_{(1,27)}=16.22\right.$, $\left.p<0.001, \eta_{p}^{2}=0.36\right)$. However, pre-tutoring math-anxiety level did not modulate the behavioral gains on either accuracy or reaction-time measures, because the interaction between Time (pre-tutoring vs post-tutoring) and Group (HMA vs LMA) was not significant for accuracy $\left(F_{(1,27)}=0.83, p=0.371\right)$ or for reaction time $\left(F_{(1,27)}=0.47, p=0.50\right)$, suggesting a comparable mathematical performance gain across HMA and LMA groups. This finding is interesting and important because, even though LMA children did not show reduced levels of anxiety toward math, they still gained comparable benefits from tutoring in behavioral performance on the arithmetic task. Finally, the two groups did not differ on accuracy pre-tutoring $\left(t_{(26)}=-1.037\right.$, $p=0.31$, Cohen's $d=0.39)$ or post-tutoring $\left(t_{(26)}=0.875, p=\right.$ 0.39 , Cohen's $d=0.32$ ). Likewise, the two groups did not differ on reaction times pre-tutoring $\left(t_{(26)}=0.291, p=0.78\right.$, Cohen's $d=0.11)$ or post-tutoring $\left(t_{(26)}=1.336, p=0.193\right.$, Cohen's $d=$ $0.50)$. These results indicate that the two groups exhibited similar mathematical performance at pre-tutoring and post-tutoring.

\section{Eight weeks of one-to-one math tutoring remediates aberrant}

functional brain responses in high math-anxious children

Next, we assessed changes in functional brain response elicited by 8 weeks of one-to-one math tutoring associated with different levels of math anxiety by examining brain activation, as measured using fMRI, during arithmetic problem solving before and after tutoring. fMRI data were analyzed at the whole-brain level contrasting Addition versus Control task conditions. A Time (pre-tutoring, post-tutoring) $\times$ Group $($ HMA, LMA) ANOVA revealed that, compared with LMA children, HMA children showed greater tutoring-induced changes. Remarkably, tutoring-induced changes in functional brain response in HMA children were characterized by normalization of aberrant functional responses to levels seen in LMA children, across distributed brain regions, including the amygdala as well as brain areas in the prefrontal and parietal cortices (Fig. 2). Specifically, before tutoring, compared with the LMA group, mathematical problem solv- ing in the HMA group was associated with significantly greater activation in the right amygdala, a region critical for emotion regulation (Phelps and LeDoux, 2005). Additionally, greater responses in the HMA group than in the LMA group were observed in the left intraparietal sulcus, the left angular gyrus, the right ventrolateral prefrontal cortex (VLPFC), the bilateral fusiform gyrus, and the bilateral superior parietal lobe-regions critical for successful math problem solving (Menon, 2014; Fig. 2). No brain regions showed lower responses in the HMA group than in the LMA group. After tutoring, no brain regions showed greater or lesser responses in the HMA group than in the LMA group, further indicating normalization of aberrant functional responses in the HMA group (Fig. 2).

To demonstrate the specificity of our findings, we performed additional control analysis. Specifically, we performed a Time (pre-tutoring, post-tutoring) $\times$ Group (HMA, LMA) ANOVA analysis with the following covariates of no interest: (1) pretutoring and post-tutoring accuracy and reaction times on the addition and the control tasks, as well as (2) tutoring-induced change in accuracy and reaction times on the addition and the control tasks. The results remained significant after controlling for these potential confounding factors, demonstrating that anxiety-related changes in functional brain response are independent of mathematical performance at pre-tutoring and posttutoring as well as tutoring-induced changes in mathematical performance, and potential differences related to task difficulty between the addition and the control tasks. Together, these results suggest that 8 weeks of one-to-one math tutoring normalizes activity levels in children with HMA to the level of their LMA peers in multiple brain systems important for emotion regulation and mathematical cognition.

\section{Remediation of aberrant amygdala reactivity predicts tutoring-} induced reductions in math anxiety

To investigate whether changes in functional brain response predicted individual differences in decrease of math anxiety with tutoring, we conducted an SVR analysis using change in functional activation with tutoring as the independent variable and change in anxiety levels with tutoring as the dependent variable. We focused on brain regions that showed greater changes in functional activation with tutoring in HMA, compared with LMA, children. This analysis revealed that tutoring-induced changes in brain activity in the right amygdala cluster predicted anxiety-level changes with tutoring in HMA children $\left[R^{2}=0.80\right.$; false discovery rate (FDR) corrected; $p<0.05$; Fig. 3]. Based on previously published cytoarchitectonic maps of the amygdala (Eickhoff et al., 2005), this cluster was localized to the basolateral nucleus of the right amygdala. The SVR results remained significant even after covarying out pre-tutoring anxiety levels, mathematical performance at pre-tutoring and post-tutoring as well as tutoring-induced performance improvements in accuracy and reaction times $\left(R^{2}=0.59\right.$; FDR corrected; $\left.p<0.05\right)$. Notably, these effects were specific to the right amygdala, as tutoringinduced changes in parietal and prefrontal regions critical for math cognition did not predict changes in anxiety levels in the HMA group. Additionally, neither IQ nor scores on Numerical Operations or Mathematical Reasoning subtests of WIAT-II (Wechsler, 2001) predicted anxiety changes with tutoring, further highlighting the specificity of the amygdala findings.

\section{Anatomical specificity of amygdala findings}

To further clarify our findings, we performed additional analysis examining neural response during arithmetic processing in brain 
Time (Pre-tutoring, Post-tutoring) X Group (HMA, LMA)

Amygdala

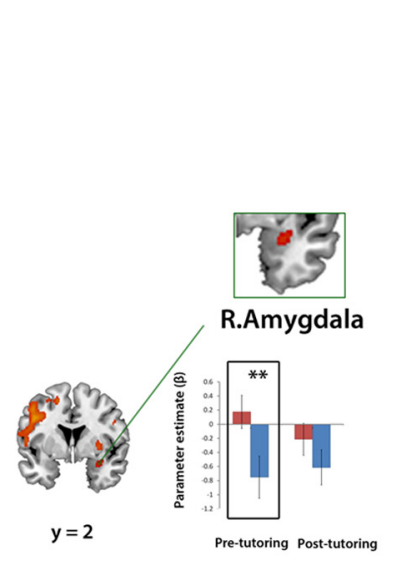

- HMA $=$ LMA
Fronto-parietal/VTOC
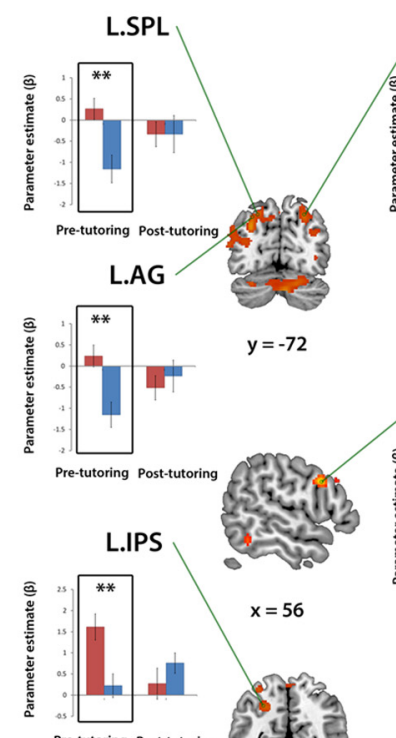

$x=56$

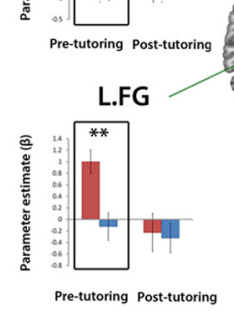

Pre-tutoring: HMA vs. LMA

Amygdala

Fronto-parietal/VTOC

R.VLPFC

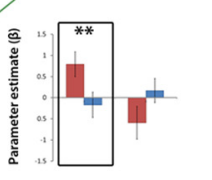

Pre-tutoring Post-tutoring
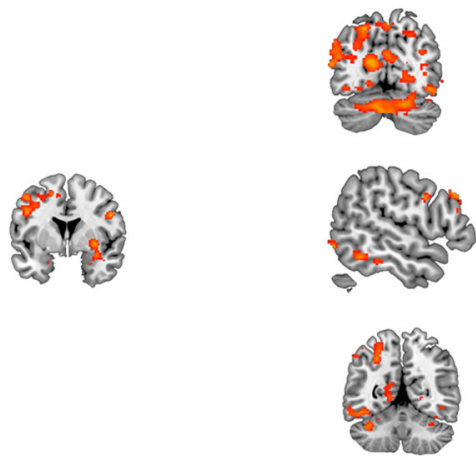

Post-tutoring: HMA vs. LMA

Amygdala

Fronto-parietal/VTOC
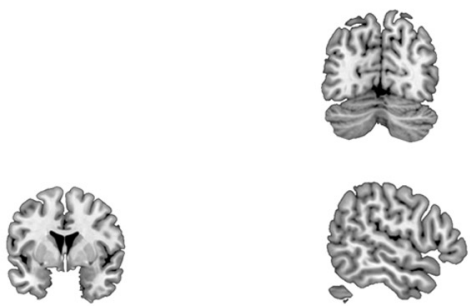
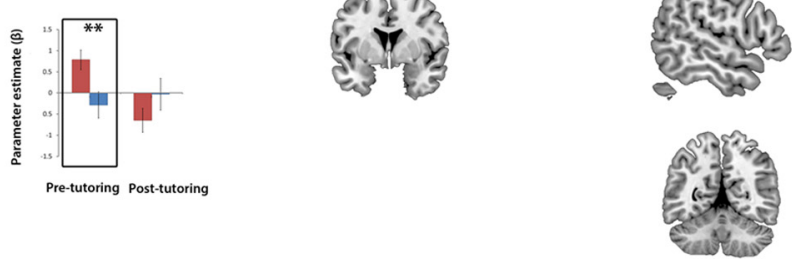

Figure 2. Eight weeks of one-to-one math tutoring remediates aberrant functional brain responses in high math-anxious children. A Time (pre-tutoring, post-tutoring) $\times$ Group (HMA, LMA) ANOVA revealed that compared with LMA children, HMA children showed greater tutoring-induced changes. Remarkably, tutoring-induced changes in functional brain response in HMA children were characterized by normalization of aberrant functional responses to levels seen in LMA children across distributed brain regions, including the amygdala as well as brain areas in the prefrontal, parietal, and ventral temporal-occipital (VTOC) cortices. Specifically, before tutoring, compared with the LMA group, the HMA group showed significantly greater activation in the right amygdala, a key brain region for processing negative emotions. Additionally, greater responses in the HMA group than in the LMA group were observed in left intraparietal sulcus (L.IPS), left angular gyrus (L.AG), right VLPFC (R.VLPFC), bilateral fusiform gyrus (L.FG and R.FG), and bilateral superior parietal lobe (L.SPL and R.SPL), regions involved in successful mathematical problem solving. No brain regions showed lesser responses in the HMA group than in the LMA group. After tutoring, no brain regions showed greater or lesser responses in the HMA group, compared with the LMA group, indicating remediation of aberrant functional responses in the HMA group. Left, Right amygdala region as well as frontoparietal/VTOC regions that showed a significant interaction between tutoring session and group. Top right, Higher functional responses in the HMA group, compared with the LMA group, within these regions, before tutoring. Bottom right, In these brain regions, there were no differences in the functional brain responses between HMA and LMA groups after tutoring $\left({ }^{* *} p<0.01\right)$.

regions identified in previous studies of high math-anxious adults by Lyon and Beilock (2012a,b). Specifically, we examined neural responses during arithmetic processing in five of their clusters-left insula ( $x=-39 \mathrm{~mm}, y=-23 \mathrm{~mm}, z=9 \mathrm{~mm})$, right insula ( $x=36 \mathrm{~mm}, y=-16 \mathrm{~mm}, z=9 \mathrm{~mm})$, right prefrontal cortex $(x=44 \mathrm{~mm}, y=13 \mathrm{~mm}, z=31 \mathrm{~mm})$, right caudate ( $x=9 \mathrm{~mm}, y=14 \mathrm{~mm}, z=2 \mathrm{~mm}$ ), and left hippocampus $(x=-23 \mathrm{~mm}, y=-23 \mathrm{~mm}, z=-5 \mathrm{~mm})$ at pre-tutoring and post-tutoring. Their right prefrontal cortex cluster overlapped with a cluster that had a peak in right VLPFC in our study—-this cluster showed hyperactivation in the HMA group compared with LMA group at pre-tutoring. There were no differences posttutoring. None of the other four clusters showed group differences either pre-tutoring or post-tutoring. Furthermore, tutoring-induced changes in the five clusters did not predict changes in anxiety levels. These results further highlight the specificity of our amygdala findings.
Eight weeks of one-to-one math tutoring remediates impaired amygdala circuits in high math-anxious children

Finally, to gain additional insights into changes in brain circuits elicited by 8 weeks of one-to-one math tutoring, we examined effective connectivity of the right amygdala during arithmetic problem solving before and after tutoring. We focused on the right amygdala cluster where tutoring-induced decreases in hyperactive responses predicted decreases in anxiety levels in HMA children. Generalized PPI (gPPI) analysis was used to investigate math-task-related influences of the right amygdala on other brain regions. The peak seed voxel of the ROI for this analysis was located in the right amygdala $(x=30 \mathrm{~mm}, y=2 \mathrm{~mm}, z=-20$ $\mathrm{mm})$. Effective connectivity was estimated at the whole-brain level, after discounting the influence of overall task-related activation and the effects of common driving inputs. A Time (pretutoring, post-tutoring) $\times$ Group (HMA, LMA) interaction analysis revealed that HMA children showed normalization of interhemispheric hyperconnectivity between the right and the 
left amygdala to the levels seen in LMA children (Fig. 4). Notably, before tutoring, the HMA group, compared with the LMA group, showed greater effective connectivity between the right and the left amygdala. In sharp contrast, after tutoring, the HMA group, compared with the LMA group, showed no differences in effective connectivity between the right amygdala and the left amygdala or any other brain region. The tutoring-induced changes in amygdala connectivity were not related with changes in the amygdala reactivity with tutoring in the HMA ( $p=$ $0.58)$, LMA $(p=0.14)$, or both groups combined $(p=0.1)$.

To further demonstrate the robustness of our connectivity analysis findings, we examined the task-related variance in the left amygdala cluster, which was removed during the gPPI analysis in the HMA and LMA groups. We found that the regressed-out task-related variance was not different between the HMA and LMA groups at pre-tutoring $\left(t_{(26)}=0.297, p=\right.$ 0.769 , Cohen's $d=0.12$ ) or post-tutoring $\left(t_{(26)}=0.792, p=0.436\right.$, Cohen's $d=$ $0.32)$. Additionally, the task-related variance did not change with tutoring in the HMA $\left(t_{(13)}=-1.073, p=0.304\right.$, Cohen's $d=$ $-0.16)$ and LMA $\left(t_{(13)}=-0.319, p=0.755\right.$, Cohen's $\left.d=-0.39\right)$ groups. A Time (pre-tutoring, post-tutoring) $\times$ Group (HMA, LMA) ANOVA analysis with task-related variance at pretutoring and post-tutoring revealed no significant Time $\times$ Group interaction $\left(F_{(1,27)}=0.13, p=0.716\right)$. These results indicate that tutoring-related changes in connectivity are independent of overall task-related activation in the amygdala.

\section{Discussion}

Our study demonstrates for the first time that 8 weeks of intensive one-to-one math tutoring reduces in elementary school children negative emotional response to math and remediates aberrant functional responses and connectivity associated with math anxiety. Before tutoring, compared with the LMA group, children in the HMA group showed aberrant, hyperactive, functional responses in the amygdala, a brain region implicated in processing negative emotions and fearful stimuli (Phelps and LeDoux, 2005). This result is consistent with evidence from a previous study, on a different group of children, which reported that childhood math anxiety is associated with hyperactivity of the amygdala (Young et al., 2012). Similar to Young et al., we also observed that the HMA group showed aberrant functional responses in multiple parietal and prefrontal regions critical for successful mathematical problem solving (Menon, 2014). Remarkably, math tutoring normalized brain activity levels in children with HMA to the level of their LMA peers in systems important for emotion and mathematical cognition. Differences in brain responses between HMA and LMA groups during arithmetic problem solving that were evident before tutoring were entirely absent after tutoring. Cognitive tutoring not only resulted in normalization of activity levels in children with HMA to levels of their LMA peers in brain areas important for numerical cognition but also in amygdala nuclei that mediate reactivity to negatively valenced stimuli. Moreover, our finding of a signifi- cant relation between the degree of brain normalization and level of anxiety reduction provides additional evidence for the behavioral significance of functional changes in HMA children with tutoring. Notably, only the amygdala showed this effect; changes in other brain regions that exhibited tutoring-induced changes, including frontal and parietal cortices involved in mathematical cognition, were not correlated with anxiety changes. Furthermore, none of the neuropsychological measures including IQ, working memory, and mathematical abilities predicted tutoringrelated anxiety changes, highlighting the specificity of our amygdala findings.

A recent study of adults with HMA found greater activity in the insula during anticipation of math problems, a finding that was attributed to subjective experience of threat and pain (Lyons and Beilock, 2012a). In the present study, we did not find greater insula activation during math problem solving in HMA children, compared with LMA children, at either the pre-tutoring or posttutoring sessions. In a different study of HMA adults, Lyon and Beilock identified additional areas in the prefrontal cortex, caudate, and hippocampus associated with math anxiety (Lyons and Beilock, 2012b). To further probe the anatomical specificity of our findings, we performed additional analysis using these brain regions. Their right prefrontal cortex cluster overlapped with a cluster that had a peak in the right VLPFC in our study-this cluster showed hyperactivation in the HMA group compared with LMA group at pre-tutoring and no differences posttutoring. None of the other regions showed group differences either pretutoring or post-tutoring. Critically, tutoring-induced changes in these regions, including the insula and right VLPFC, did not predict reductions in math anxiety in the HMA group. These results further highlight the specificity of our amygdala findings.

Connectivity analysis further revealed that 8 weeks of intensive one-to-one math tutoring normalizes impaired functional circuits anchored in the amygdala in children with HMA to the level of their LMA peers. Notably, differences in the effective 
Time (Pre-tutoring, Post-tutoring) X Group (HMA, LMA)

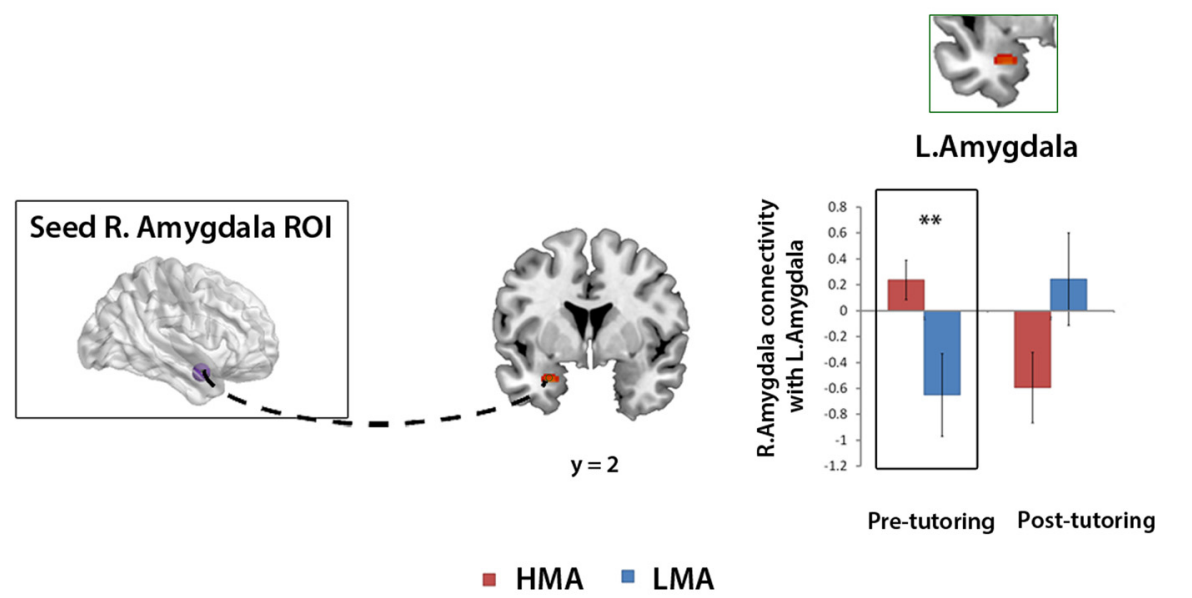

Pre-tutoring: HMA vs. LMA

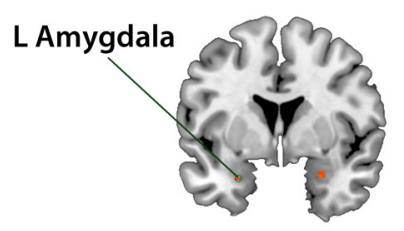

Post-tutoring: HMA vs. LMA

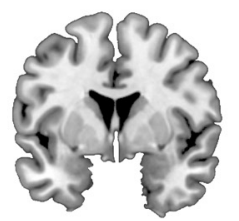

Figure 4. Eight weeks of one-to-one math tutoring remediates impaired functional brain circuits anchored in the amygdala in HMA children. A Time (pre-tutoring, post-tutoring) $\times$ Group (HMA, LMA) interaction analysis revealed that HMA children showed normalization of interhemispheric hyperconnectivity between the right and the left amygdala to the levels seen in LMA children. Notably, before tutoring, children in the HMA group showed greater effective connectivity between the right and the left amygdala during mathematical problem solving when compared with the LMA group. After tutoring, differences in effective connectivity of the amygdala that were evident before tutoring were entirely absent, suggesting remediation of impaired functional brain circuits in the HMA group. Left, Right amygdala seed region $(x=30 \mathrm{~mm}, y=2 \mathrm{~mm}, z=-20 \mathrm{~mm})$ used in the effective connectivity analysis and the left amygdala region $(x=-26 \mathrm{~mm}, y=2 \mathrm{~mm}, z=$ $-24 \mathrm{~mm}$ ) that showed a significant interaction between tutoring session and group. Top right, Higher effective connectivity in the HMA group, compared with the LMA group, between the right amygdala and the left amygdala before tutoring. Bottom right, After tutoring, there were no differences in the effective connectivity between the HMA and LMA groups, between the right amygdala and the left amygdala $\left({ }^{* *} p<0.01\right)$.

connectivity of the amygdala during arithmetic problem solving between HMA and LMA groups that were evident before tutoring were entirely absent after tutoring. Before tutoring, during mathematical problem solving, children in the HMA group, compared with the LMA group, showed greater effective connectivity between the right and the left amygdala, consistent with findings from Young et al. (2012). These results demonstrate for the first time that intensive math tutoring also remediates functional circuit impairments associated with math anxiety.

Our study provides novel evidence that an intensive well validated math-tutoring program not only reduces math anxiety but also normalizes atypical functional responses and connectivity in emotion-related circuits anchored in the amygdala and in the frontoparietal mathematical information processing system. Why does an 8 week math-tutoring program reduce math anxiety? We suggest that the intensive math-tutoring program repeatedly exposes children to what they fear: mathematical stimuli and social situations involving mathematical problem solving. Repeated exposure can make the child feel more in control of situations involving mathematical problem solving, thereby diminishing their math anxiety. This view is supported by previous work showing that exposure-based therapy is one of the most effective treatments for anxiety disorders (Van Etten and Taylor, 1998; Wolitzky-Taylor et al., 2008). Crucially, as our study demonstrates, analogous to treatments for other anxiety disorders, reductions in math anxiety rely on a common mechanism that operates via alterations in amygdala response and connectivity (Abramowitz et al., 2011).

Our findings of exposure-related changes in amygdala response are also consistent with a large body of animal research. In the present study, we observed that repeated exposure to math problems delivered through intensive one-to-one tutoring reduced hyperactivity in local amygdala circuits. Consistent with our finding of tutoring-induced decreases in amygdala hyperactivation, studies in animal models have shown that exposure to anxiety-provoking stimuli reduces neuronal firing rates in the amygdala (Myers and Davis, 2007). Recent studies in animal models have also identified underlying synaptic mechanisms: exposure induces change in the amygdala by remodeling inhibitory connections in local circuits to silence neurons associated with fear and anxiety (Trouche et al., 2013). Extrapolating from these studies, we posit that similar mechanisms may contribute to the suppression of anxious responses in HMA children. The observed normalization of functional circuits between the right and left amygdala further suggests that inhibitory synaptic activity within the right amygdala also influences interhemispheric functional interactions, further contributing to reduced negative reactivity. This view is consistent with evidence, based on optogenetic manipulation in animal models, that such reductions in amygdala hyperactivity and hyperconnectivity are anxiolytic (Janak and Tye, 2015).

Our study also provides novel insights into why some HMA children exhibit reductions in anxiety levels with tutoring while others do not. Specifically, using multivariate pattern analysis, we observed that the amount of change in activity in the basolateral nucleus of the amygdala with tutoring is a key determinant of affective response to the intervention. The predictive role of amygdala observed here is strikingly similar to previous findings in 7-9-year-old children that suggested structural and functional organization of the basolateral amygdala can reliably predict individual differences in generalized childhood anxiety (Qin et al., 2014). Here, we extend this finding to math-anxiety-related response to cognitive intervention, further suggesting that basolateral amygdala is a locus of individual differences in anxiety reduction. We suggest that brain-based biomarkers of response to intervention along with the novel multivariate machine learning approach developed here will be useful in developing and monitoring more personalized interventions for treating math anxiety as well as other anxiety disorders.

Further studies are needed to investigate whether cognitive tutoring and exposure can also remediate math anxiety in ado- 
lescents and adults and whether they operate via mechanisms similar to those identified in children here. Behavioral studies have reported that math anxiety in college students can be reduced by instructing them to write freely about their emotions with respect to an upcoming math situation (Park et al., 2014). Such reappraisal and reframing techniques can help curtail negative thoughts and emotions and improve test performance in stressful situations (Ramirez and Beilock, 2011). A more recent behavioral study found that math anxiety can be ameliorated and arithmetic performance can be improved in HMA adults by applying transcranial direct-current stimulation (tDCS) to the dorsolateral prefrontal cortex (Sarkar et al., 2014). However, the same procedure also increased math anxiety and impaired arithmetic performance in LMA adults. Further studies in children, adolescents, and adults are required to characterize the relative efficacy and stability of exposure, reappraisal, and tDCS-based techniques for reducing math anxiety, while simultaneously improving math skills, at different developmental stages. An important question here is whether young children can use appraisal strategies effectively to reduce math anxiety, given their limited cognitive and affective control abilities (Zelazo et al., 2004). Further work is also needed to investigate the long-term stability of anxiety reductions observed with tutoring, potential placebo effects (Boot et al., 2013), and generalization to more complex math problems.

In conclusion, the present study is the first to demonstrate the unique potential of short intensive math-tutoring programs to help children who struggle with math anxiety. It is both surprising and encouraging that a cognitive tutoring protocol designed to improve mathematical problem-solving skills also reduces math anxiety in young children by mere exposure. These changes are supported by functional changes in emotion-related circuits anchored in the amygdala. Our findings that the effects of math anxiety can be reduced at both the behavioral and neurobiological levels provide an important new template to guide and propel further research into its diagnosis and treatment. Crucially, ameliorating the negative impact of math anxiety in early childhood has far-reaching implications for improving each individual's academic and professional success in today's technological society, which increasingly demands strong quantitative skills.

\section{References}

Abramowitz J, Deacon B, Whiteside S (2011) Exposure therapy for anxiety: principles and practice. New York: Guilford.

Ashcraft M, Battaglia J (1978) Cognitive arithmetic: evidence for retrieval and decision processes in mental addition. J Exp Psychol 4:527-538. CrossRef

Ashcraft MH, Krause JA (2007) Working memory, math performance, and math anxiety. Psychon Bull Rev 14:243-248. CrossRef Medline

Beilock SL, Willingham DT (2014) Math anxiety: can teachers help students reduce it? Am Educator 38:28-32.

Boot WR, Simons DJ, Stothart C, Stutts C (2013) The pervasive problem with placebos in psychology: why active control groups are not sufficient to rule out placebo effects. Perspect Psychol Sci 8:445-454. CrossRef Medline

Coccaro EF, McCloskey MS, Fitzgerald DA, Phan KL (2007) Amygdala and orbitofrontal reactivity to social threat in individuals with impulsive aggression. Biol Psychiatry 62:168-178. CrossRef Medline

Cox RW (1996) AFNI: software for analysis and visualization of functional magnetic resonance neuroimages. Comput Biomed Res 29:162-173. CrossRef Medline

Eickhoff SB, Stephan KE, Mohlberg H, Grefkes C, Fink GR, Amunts K, Zilles K (2005) A new SPM toolbox for combining probabilistic cytoarchitectonic maps and functional imaging data. Neuroimage 25:1325-1335. CrossRef Medline
Friston KJ, Buechel C, Fink GR, Morris J, Rolls E, Dolan RJ (1997) Psychophysiological and modulatory interactions in neuroimaging. Neuroimage 6:218-229. CrossRef Medline

Fuchs LS, Powell SR, Hamlett CL, Fuchs D, Cirino PT, Fletcher JM (2008) Remediating computational deficits at third grade: a randomized field trial. J Res Educ Eff 1:2-32. Medline

Fuchs LS, Geary DC, Compton DL, Fuchs D, Schatschneider C, Hamlett CL, Deselms J, Seethaler PM, Wilson J, Craddock CF, Bryant JD, Luther K, Changas P (2013) Effects of first-grade number knowledge tutoring with contrasting forms of practice. J Educ Psychol 105:58-77. CrossRef Medline

Gamer M, Büchel C (2009) Amygdala activation predicts gaze toward fearful eyes. J Neurosci 29:9123-9126. CrossRef Medline

Glover GH, Lai S (1998) Self-navigated spiral fMRI: interleaved versus single-shot. Magn Reson Med 39:361-368. CrossRef Medline

Hauner KK, Mineka S, Voss JL, Paller KA (2012) Exposure therapy triggers lasting reorganization of neural fear processing. Proc Natl Acad Sci U S A 109:9203-9208. CrossRef Medline

Hembree R (1990) The nature, effects, and relief of mathematics anxiety. J Res Math Ed 21:33-46. CrossRef

Hooker CI, Germine LT, Knight RT, D’Esposito M (2006) Amygdala response to facial expressions reflects emotional learning. J Neurosci 26: 8915-8922. CrossRef Medline

Janak PH, Tye KM (2015) From circuits to behaviour in the amygdala. Nature 517:284-292. CrossRef Medline

Kao MH, Mandal A, Lazar N, Stufken J (2009) Multi-objective optimal experimental designs for event-related fMRI studies. Neuroimage 44:849856. CrossRef Medline

Kim DH, Adalsteinsson E, Glover GH, Spielman DM (2002) Regularized higher-order in vivo shimming. Magn Reson Med 48:715-722. CrossRef Medline

Lyons IM, Beilock SL (2012a) When math hurts: math anxiety predicts pain network activation in anticipation of doing math. PLoS One 7:e48076. CrossRef Medline

Lyons IM, Beilock SL (2012b) Mathematics anxiety: separating the math from the anxiety. Cereb Cortex 22:2102-2110. CrossRef Medline

Ma X (1999) Meta-analysis of the relationship between anxiety toward mathematics and achievement in mathematics. J Res Math Ed 30:520 540. CrossRef

Maloney EA, Beilock SL (2012) Math anxiety: who has it, why it develops, and how to guard against it. Trends Cogn Sci 16:404-406. CrossRef Medline

Menon V (2014) Arithmetic in the child and adult brain. Oxford: Oxford UP.

Myers KM, Davis M (2007) Mechanisms of fear extinction. Mol Psychiatry 12:120-150. CrossRef Medline

Park D, Ramirez G, Beilock SL (2014) The role of expressive writing in math anxiety. J Exp Psychol Appl 20:103-111. CrossRef Medline

Pessoa L, McKenna M, Gutierrez E, Ungerleider LG (2002) Neural processing of emotional faces requires attention. Proc Natl Acad Sci U S A 99: 11458-11463. CrossRef Medline

Phelps EA, LeDoux JE (2005) Contributions of the amygdala to emotion processing: from animal models to human behavior. Neuron 48:175-187. CrossRef Medline

Pickering S, Gathercode SE (2001) Working memory test battery for children. London: Psychological Corporation.

Powell SR, Fuchs LS, Fuchs D, Cirino PT, Fletcher JM (2009) Effects of fact retrieval tutoring on third-grade students with math difficulties with and without reading difficulties. Learn Dis Res Pract 24:1-11.

Preston AR, Bornstein AM, Hutchinson JB, Gaare ME, Glover GH, Wagner AD (2010) High-resolution fMRI of content-sensitive subsequent memory responses in human medial temporal lobe. J Cogn Neurosci 22:156-173. CrossRef Medline

Qin S, Young CB, Duan X, Chen T, Supekar K, Menon V (2014) Amygdala subregional structure and intrinsic functional connectivity predicts individual differences in anxiety during early childhood. Biol Psychiatry 75: 892-900. CrossRef Medline

Ramirez G, Beilock SL (2011) Writing about testing worries boosts exam performance in the classroom. Science 331:211-213. CrossRef Medline

Sarkar A, Dowker A, Cohen Kadosh R (2014) Cognitive enhancement or cognitive cost: trait-specific outcomes of brain stimulation in the case of mathematics anxiety. J Neurosci 34:16605-16610. CrossRef Medline

Summerfield C, Greene M, Wager T, Egner T, Hirsch J, Mangels J (2006) 
Neocortical connectivity during episodic memory formation. PLoS Biol 4:e128. CrossRef Medline

Supekar K, Swigart AG, Tenison C, Jolles DD, Rosenberg-Lee M, Fuchs L, Menon V (2013) Neural predictors of individual differences in response to math tutoring in primary-grade school children. Proc Natl Acad Sci U S A 110:8230-8235. CrossRef Medline

Trouche S, Sasaki JM, Tu T, Reijmers LG (2013) Fear extinction causes target-specific remodeling of perisomatic inhibitory synapses. Neuron 80:1054-1065. CrossRef Medline

Valet M, Sprenger T, Boecker H, Willoch F, Rummeny E, Conrad B, Erhard P, Tolle TR (2004) Distraction modulates connectivity of the cingulofrontal cortex and the midbrain during pain-an fMRI analysis. Pain 109:399-408. CrossRef Medline

Van Etten M, Taylor S (1998) Comparative efficacy of treatments for posttraumatic stress disorder: a meta-analysis. Clin Psychol Psychother 5:126-144. CrossRef

Vuilleumier P, Armony JL, Driver J, Dolan RJ (2001) Effects of attention and emotion on face processing in the human brain: an event-related fMRI study. Neuron 30:829-841. CrossRef Medline

Wechsler D (1999) Wechsler abbreviated scale of intelligence. San Antonio, TX: Psychological Corporation.

Wechsler D (2001) The Wechsler Individual Achievement Test-Second Edition (WIAT-II). San Antonio, TX: Psychological Corporation.

Wolitzky-Taylor KB, Horowitz JD, Powers MB, Telch MJ (2008) Psychological approaches in the treatment of specific phobias: a meta-analysis. Clin Psychol Rev 28:1021-1037. CrossRef Medline

Wu SS, Barth M, Amin H, Malcarne V, Menon V (2012) Math anxiety in second and third graders and its relation to mathematics achievement. Front Psychol 3:162. CrossRef Medline

Young CB, Wu SS, Menon V (2012) The neurodevelopmental basis of math anxiety. Psychol Sci 23:492-501. CrossRef Medline

Zelazo PD, Craik FI, Booth L (2004) Executive function across the life span. Acta Psychologica 115:167-183. CrossRef Medline 